\title{
Report of envenomation in humans by handling a dyeing poison frog Dendrobates tinctorius (SCHNEIDER, 1799) (Anura: Dendrobatidae) in the Amazon, Brazil
}

\author{
Bruno Alessandro Augusto Peña Corrêa ${ }^{[1]}$, Vitor Matheus Alcântara de Sena ${ }^{[2],}$ \\ Rubens Hisanari Matsushita ${ }^{[3]}$ and Nathalie Kaladinsky Citeli ${ }^{[4]}$
}

\author{
[1]. Universidade de Brasília, Laboratório de Anatomia Comparada, Brasília, DF, Brasil. \\ [2]. Universidade de Brasília, Laboratório de Planejamento para a Conservação da Biodiversidade, Brasília, DF, Brasil. \\ [3]. Freelance Researcher, Brasil. \\ [4]. Universidade de Brasília, Laboratório de Fauna e Unidades de Conservação, Brasília, DF, Brasil.
}

\begin{abstract}
We report a case of envenomation by Dendrobates tinctorius in the northwest of the Amazon Forest. The patients were two men, who presented with numbness in the right arm and slight numbness in the lower lip, respectively. Dendrobates tinctorius secretions contain pumiliotoxin, one of several toxins found in the dendrobatidis skin, which interferes with muscle contraction and causes locomotor difficulties. Although Dendrobatidae is a family of anurans known for their venom, few studies describe the symptoms of envenomation in humans.
\end{abstract}

Keywords: Amphibians. Injuries. Hypesthesia.

\section{INTRODUCTION}

Amphibians have a range of defense mechanisms against predators, among which is the presence of toxins in their $\operatorname{skin}^{1}$. Such poisons can be produced by the animals themselves or obtained from their food (e.g., anurans of the family Dendrobatidae), and can be stored along its whole body or in specific regions such as the paratoid glands in some species (e.g., toads of the family Bufonidae and salamanders $)^{1,2}$. The Dendrobatidae family comprises 202 species of aposematic anurans ${ }^{3}$. Aposematic refers to an animal which uses colors or shapes to warn potential predators that they have defense mechanisms, such as venoms ${ }^{1}$. Their skin toxins can be composed of several distinct classes of alkaloid compounds (batrachotoxins, histrionicotoxins, pumiliotoxin $\mathrm{C}$, and the pumiliotoxin A family, gephyrotoxins, and a group of indolicizidines $)^{4,5}$.

Alkaloids are basic chemical compounds, made from amines, which are found mainly in plants, and can be sequestered by animals such as ants, bettles, termites, and other invertebrates ${ }^{6,7}$.

\footnotetext{
Corresponding author: Bruno Alessandro Augusto Peña Corrêa.

e-mail: brunobio.unb@gmail.com

(iD) https://orcid.org/0000-0002-1876-5162

Received 14 July 2020

Accepted 3 August 2020
}

The Dendrobatidae family's specialized diet in ants allows for the acquisition of alkaloids for defense mechanisms and the evolution of aposematic forms ${ }^{6}$. The dyeing poison frog Dendrobates tinctorius (Cuvier, 1797), is a medium-sized frog that can be found in open areas of the Amazon Forest. It is a diurnal species with a wide occurrence in Central America, French Guiana, Suriname, and in the north of Brazil $^{8}$. The main alkaloid carried by this species is pumiliotoxin (PTX), which is highly toxic in high concentrations ${ }^{4}$. PTX interferes with muscle contraction by affecting calcium channels, causing locomotor difficulties, clonic convulsions, paralysis, or even death, depending on the affected organism ${ }^{4}$. Here, we report and describe the symptoms of two human envenomations by Dendrobates tinctorius.

\section{CASE REPORT}

The incident occurred on 4th August 2013 at 11:40 a.m., near the city of Monte Dourado, Pará, Brazil. Two photographers, 47 and 30 years old, were walking on a trail when one of them spotted a D. tinctorius (Figure 1) next to a tree trunk. Even though they identified the frog as being from the Dendrobatidae family, they touched it so they would be able to photograph it. The first photographer quickly captured the frog and held it for about five seconds with his own hands, before releasing it and washing his hands in a nearby stream. The other photographer then kept the frog from moving by placing both his hands on top. Neither of the photographers suffered hand injuries. 


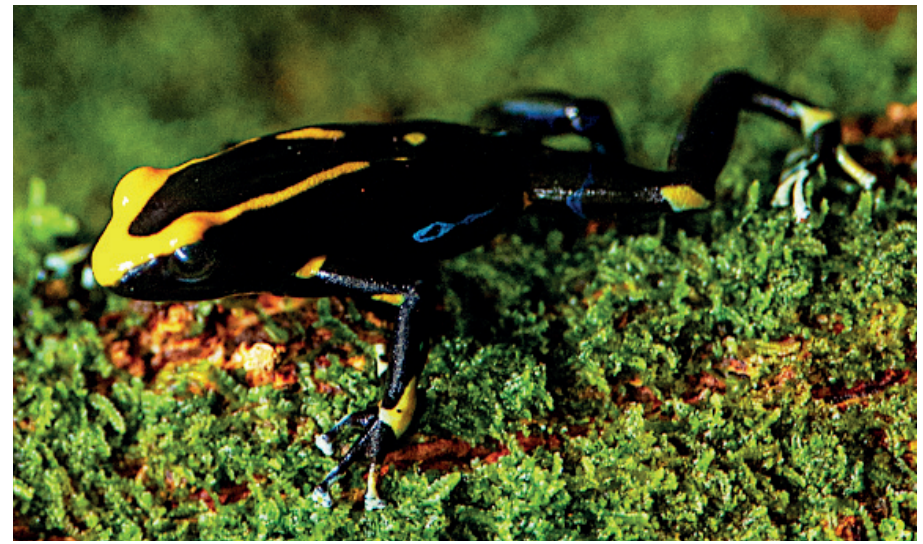

FIGURE 1: Dendrobates tinctorius specimen handled by the photographers.

Both men photographed the tree-frog for about five minutes, without touching it again. However, 20 minutes after the first contact with the anuran, the photographer who initially handled it began to feel numbness in his right arm, mainly at the height of the forearm.

The other photographer, who after taking photos had touched his mouth without first washing his hands, felt a slight numbness in his lower lip. The pair reported that they did not seek medical attention because the numbness was mild and after about $40 \mathrm{~min}$ they no longer felt symptoms. Species identification was carried out by Dr. Carlos Eduardo Costa de Campos, professor at the Federal University of Amapá (Herpetology Laboratory), and the tree frog was not collected.

\section{DISCUSSION}

Accidents involving amphibians in Brazil are not listed by the Brazilian Ministry of Health in its list of human intoxications ${ }^{10}$. Uncommon, medically relevant accidents involving humans and anurans occur with field workers or due to the increasing use of frog's toxins by inexperienced practitioners in rituals, such as "kambô""1,12.

In our report, the photographer's symptoms could have been aggravated if contact with the animal had lasted longer or if there had been a wound at the points of contact.

The $D$. tinctorius toxin can lead to cardio-respiratory problems, mainly through the neurotoxic action of the poison, which affects the sodium and potassium channels, impairing muscle contraction and, consequently, the heart and breathing muscles ${ }^{4}$.

Although anurans in this family are considered a health risk, there are few studies on the substances found in the skin of D. tinctorius and even fewer studies on their physiology ${ }^{7}$. For example, approximately $37 \%$ of the alkaloids found in Dendrobatidae are unclassified, with over 250 alkaloids of unknown structural class awaiting chemical characterization ${ }^{2,7}$.
Regardless, the handling of this species requires special attention, and the risk of potential envenomation should be taken into account. In case of accidents, we strongly recommend reporting to health authorities so that possible side effects and negative outcomes can be clearly documented.

\section{ACKNOWLEDGMENTS}

We thank Professor Carlos E. Costa de Campos professor on the Federal University of Amapá for identifying the anuran.

\section{AUTHORS' CONTRIBUTION}

All authors wrote and revised the manuscript. The author of the photo is the author Rubens H. Matsushita.

\section{CONFLICT OF INTEREST}

The authors declare there are no conflicts of interest.

\section{REFERENCES}

1. Duellman WE, Trueb L. Biology of amphibians. Johns Hopkins University Press; $1994.670 \mathrm{p}$.

2. Saporito RA, Donnelly MA, Spande TF, Garraffo HM. A review of chemical ecology in poison frogs. Chemoecology. 2012;22(3):159-68.

3. Frost DR. 2020. Amphibian Species of the World: an Online Reference [Internet]. New York: American Museum of Natural History; 2020 [updated 2020 June 30; cited 2020 Jun 30]. Available from: https:// amphibiansoftheworld.amnh.org/index.php.

4. Daly JW. Alkaloids of neotropical poison frogs (Dendrobatidae). In: Kinghorn AD, Falk H, Gibbons S, Kobayashi J, editors. Fortschritte der Chemie organischer Naturstoffe/Progress in the Chemistry of Organic Natural Products. Vienna: Springer;1982. p. 205-340.

5. Schwartz CA, Castro MDS, Júnior OP, Maciel NM, Schwartz ENF, Sebben A. Princípios bioativos da pele de anfíbios: panorama atual e perspectivas. In: Nascimento LB, Oliveira ME, editors. Herpetologia no Brasil II. Belo Horizonte: Sociedade Brasileira de Herpetologia; 2007. p. 146-68.

6. Darst CR, Menéndez-Guerrero PA, Coloma LA, Cannatella, DC Evolution of dietary specialization and chemical defense in poison frogs (Dendrobatidae): a comparative analysis. Am Nat. 2005;165(1):56-69.

7. Santos JC, Tarvin RD, O'Connell LA. A review of chemical defense in poison frogs (Dendrobatidae): ecology, pharmacokinetics, and autoresistance. In: Buesching C, editors. Chemical signals in vertebrates. 13th ed. Cham: Springer; 2016. p. 305-37.

8. Born M, Bongers F, Poelman EH, Sterck FJ. Dry-season retreat and dietary shift of the dart-poison frog Dendrobates tinctorius (Anura: Dendrobatidae). J Herpetol. 2010;9(1):37-52.

9. Sistema Nacional de Informações Tóximo-Farmacológicas (SINITOX) Casos, Óbitos e Letalidade de Intoxicação Humana por Agente e por Região. Brasil [Internet]; 2017 [acessed 2020 June 26; cited 2020 Jun 26]. Available from: https://sinitox.icict.fiocruz.br/dados-nacionais.

10. Byard RW. Is voluntary envenomation from the kambô ritual therapeutic or toxic?. Forensic Sci Med Pathol. 2019;16:205-6.

11. Silva FVA, Monteiro WM, Bernarde PS. "Kambô" frog (Phyllomedusa bicolor): use in folk medicine and potential health risks. Rev Soc Bras Med Trop. 2019;52:e20180467. 